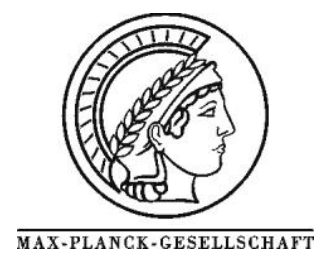

\title{
Active coke: Carbonaceous materials as catalysts for alkane dehydrogenation
}

\author{
J. McGregor ${ }^{\mathrm{a} *}$, Z. Huang ${ }^{\mathrm{a}}$, E. P.J. Parrott ${ }^{\mathrm{a}, \mathrm{b}}$, J. A. Zeitler ${ }^{\mathrm{a}}$, K. L. Nguyen ${ }^{\mathrm{a}}$, J. M. Rawson ${ }^{\mathrm{c}}$, A. Carley ${ }^{\mathrm{e}}$, T. \\ W. Hansen ${ }^{f \#}$, J.-P. Tessonnier ${ }^{f}$, D. S. Su ${ }^{f}$, D. Teschner ${ }^{f}$, E. M. Vass ${ }^{\mathrm{f}+}$, A. Knop-Gericke ${ }^{\mathrm{f}}$, \\ R. Schlögl ${ }^{\mathrm{f}}$, L. F. Gladden ${ }^{\mathrm{a}}$
}

${ }^{a}$ University of Cambridge, Department of Chemical Engineering and Biothechnology, Cambridge, CB2 3RA, UK

${ }^{\mathrm{b}}$ University of Cambridge, Cavendish Laboratory, Cambridge, CB3 OHE, UK

${ }^{\mathrm{c}}$ University of Cambridge, Department of Chemistry, Cambridge, CB2 1EW, UK

${ }^{\mathrm{e}}$ Cardiff University, School of Chemistry, Cardiff, CF10 3AT, UK

${ }^{\mathrm{f}}$ Fritz-Haber-Institut der Max-Planck-Gesellschaft, Berlin, D-14195, Germany

* Corresponding author: e-mail jm405@cam.ac.uk,

Received 29 August 2009; revised 12 November 2009; accepted 17 November 2009; available online 6 January 2010

\begin{abstract}
The catalytic dehydrogenation (DH) and oxidative dehydrogenation (ODH) of light alkanes are of significant industrial importance. In this work both carbonaceous material deposited on $\mathrm{VO}_{x} / \mathrm{Al}_{2} \mathrm{O}_{3}$ catalysts during reaction and unsupported carbon nanofibres (CNFs) are shown to be active for the dehydrogenation of butane in the absence of gas-phase oxygen. Their activity in these reactions is shown to be dependent upon their structure, with different reaction temperatures yielding structurally different coke deposits. Terahertz time-domain spectroscopy (THz-TDS), among other techniques, has been applied to the characterisation of these deposits - the first time this technique has been employed in coke studies. TEM and other techniques show that coke encapsulates the catalyst, preventing access to $\mathrm{VO}_{x}$ sites, without a loss of activity. Studies on CNFs confirm that carbonaceous materials act as catalysts in this reaction. Carbon-based catalysts represent an important new class of potential catalysts for DH and $\mathrm{ODH}$ reactions.
\end{abstract}

Keywords: Vanadia catalysts; Carbon nanofibres; THz time domain spectroscopy; Coke; Transmission electron microscopy; Butane dehydrogenation; X-ray absorption spectroscopy

\section{Introduction}

The catalytic dehydrogenation (DH) of light alkanes in the absence of oxygen is employed as an industrial process to synthesise alkenes and alkadienes, important precursor molecules for synthetic rubbers, plastics and a variety of other products. As such, annual consumption (2003) of propane and $n$-butane feedstocks for these reactions exceeds $10 \mathrm{Mt}$ [1]. Recent research in this area has focused on butane DH over alumina-supported vanadia catalysts [2-8]. Additionally, the oxidative dehydrogenation (ODH) of light alkanes also receives significant academic attention [9-12].
However, the relatively low yields achieved in the latter approach mean that this process is yet to be implemented commercially [13]. In this work, we show for the first time that carbonaceous material, coke, deposited during reaction over $\mathrm{VO}_{\mathrm{x}} / \mathrm{Al}_{2} \mathrm{O}_{3}$ can act as an active catalyst in the nonoxidative dehydrogenation of $n$-butane. This conclusion is confirmed through a comparison of the activity of coked $\mathrm{VO}_{\mathrm{x}} / \mathrm{Al}_{2} \mathrm{O}_{3}$ and carbon nanofibres. To this end a wide number of advanced techniques are employed including the first application of terahertz time-domain spectroscopy ( $\mathrm{THz}-$ TDS) in the study of coke.

The role of carbonaceous deposits in DH and ODH reactions has been the subject of extensive research. In the 
case of industrial alkane dehydrogenation significant coke deposition causes rapid deactivation of the catalyst. For instance, the CATADIENE process (ABB Lummus) employs a $\mathrm{CrO}_{\mathrm{x}} / \mathrm{Al}_{2} \mathrm{O}_{3}$ catalyst operating at $873 \mathrm{~K}$ : this catalyst requires regeneration after $\sim 10 \mathrm{~min}$ on stream as a result of coke build-up causing deactivation [1]. Laboratory studies of $\mathrm{VO}_{\mathrm{x}} / \mathrm{Al}_{2} \mathrm{O}_{3}$ catalysts have drawn correlations between the nature of the supported $\mathrm{VO}_{\mathrm{x}}$ units and the structure of the coke formed [5]. In contrast to many other reaction systems however, in $\mathrm{DH}$ reactions polyaromatic coke deposits are not always directly implicated in catalyst deactivation. Recent studies have demonstrated that such large ensembles play only a minor role in deactivation during $n$-butane dehydrogenation. Instead, the observed loss in activity can be assigned to the presence of tightly bound reaction intermediates, irreversibly adsorbed onto catalytic active sites under reaction conditions [4]. Furthermore, in the oxidative dehydrogenation of ethylbenzene, such carbonaceous deposits are not only not implicated in catalyst deactivation, but instead have been suggested as being catalytically active in their own right, a conclusion reinforced by studies on activated carbon catalysts [14-21] and nanostructured carbon materials [22-24]. More recently carbonaceous materials have also been shown to be active in the $\mathrm{ODH}$ of $n$-butane [25]. Ketonic $\mathrm{C}=\mathrm{O}$ functionalities on the surface of CNTs are believed to be the active site in this system. Notably, significant deactivation was not observed over a period of $100 \mathrm{~h}$

A wide range of experimental techniques have been applied to the study of coke and carbonaceous materials in the literature. One reason for this is that no single technique can provide the wealth of information required to understand the nature of such complex structures. For this reason, in this work we have applied a number of complementary techniques to the study of coke formed over $\mathrm{VO}_{\mathrm{x}} / \mathrm{Al}_{2} \mathrm{O}_{3}$ during butane dehydrogenation. One such method is THz-TDS, and this work represents the first application of this spectroscopy in the study of coke.

\section{Experimental}

\subsection{Materials}

The principal catalyst employed in the work reported herein is an alumina-supported vanadia catalyst with a vanadium loading of $3.5 \mathrm{wt} \%$, hereafter referred to as $\mathrm{VO}_{\mathrm{x}} / \mathrm{Al}_{2} \mathrm{O}_{3}$. This catalyst has previously been described in the literature $[2-5,26]$, and was prepared by incipient wetness impregnation employing aqueous $\mathrm{NH}_{4} \mathrm{VO}_{3}(>99 \%$, Aldrich). The alumina support is $\theta-\mathrm{Al}_{2} \mathrm{O}_{3}$ (Johnson Matthey, UK, BET surface area $=101 \mathrm{~m}^{2} \mathrm{~g}^{-1}$, pore volume $=0.60 \mathrm{ml} \mathrm{g}^{-1}$ ). Oxalic acid (99\% Aldrich) was added to the impregnation solution to ensure the dissolution of $\mathrm{NH}_{4} \mathrm{VO}_{3}\left[\mathrm{NH}_{4} \mathrm{VO}_{3}\right.$ /oxalic acid $=0.5$ (molar ratio) $]$. After impregnation the catalyst precursor was mixed thoroughly for $2 \mathrm{~h}$ at $350 \mathrm{~K}$ to ensure a more homogeneous distribution of vanadia on the support. The catalyst was then dried in air at $393 \mathrm{~K}$ overnight and calcined for $6 \mathrm{~h}$ at $823 \mathrm{~K}$, again in air. Prior to use the catalyst extrudates were ground and sieved to a particle size of 75-90 $\mu \mathrm{m}$. Additional catalytic tests have been conducted over a carbon nanofibre (CNF) material (PR24-LHT, Pyrograf Products Inc.). Full details about the synthesis and the structure of these nanofibres can be found in the review by Tibbetts et al.[27].

A number of model compounds have been studied by THz-TDS in order to assist in the interpretation of spectra. These are anthracene (99\%), phenanthrene (99.5\%), 2,3benzanthracene (98\%), 1,2-benzanthracene (99\%), triphenylene (98\%), chrysene (98\%), coronene (97\%) and graphite (all Sigma-Alrich).

\subsection{Catalytic Activity Measurements}

Catalytic activity data were acquired using a fixedbed, continuous flow reactor connected to an on-line GC (Agilent 6890 Series, FID, column Agilent HP-5). The catalyst $\left(1.5 \mathrm{~cm}^{3}\right)$ was heated $\left(5 \mathrm{~K} \mathrm{~min}^{-1}\right)$ to $973 \mathrm{~K}$ in $5 \% \mathrm{O}_{2} / \mathrm{N}_{2}\left(0.5 \mathrm{barg}, 40 \mathrm{ml} \mathrm{min}^{-1}\right)$ and held at this temperature for $2 \mathrm{~h}$. A flow of $\mathrm{He}\left(0.5 \mathrm{barg}, 42 \mathrm{ml} \mathrm{min}^{-1}\right)$ was then established and the temperature adjusted to the desired reaction temperature (at least $30 \mathrm{~min}$ ). For reactions over the CNF the pre-treatment step was conducted in flowing $\mathrm{He}\left(0.5 \mathrm{barg}, 42 \mathrm{ml} \mathrm{min}^{-1}\right)$ in place of $\mathrm{O}_{2} / \mathrm{N}_{2}$ to avoid functionalisation or combustion of the nanofibres. In all cases, $3 \% n-\mathrm{C}_{4} \mathrm{H}_{10} / \mathrm{N}_{2}$ was then introduced (0.5 barg, $60 \mathrm{ml} \mathrm{min}^{-1}$ ) for a period of $180 \mathrm{~min}$. GC measurements were taken at regular intervals. Conversion, yield of $\mathrm{C}_{4}$ hydrocarbons and selectivity to 1-butene and 1,3-butadiene were calculated using equations 1-3 respectively. After 180 min the catalyst was cooled to room temperature in flowing He and removed for ex situ analysis. Conversion, yield and selectivity are defined as follows:

$$
\begin{aligned}
& \% \text { Conversion }=100 \times\left[\frac{\text { no. of moles of butane consumed }}{\text { no.of moles of butane introduced }}\right] \\
& \% \text { Yield }=100 \times\left[\frac{\text { no. of moles of product formed }}{\text { no. of moles of butane introduced }}\right] \\
& \% \text { Selectivity }=100 \times\left[\frac{\text { no. of moles of product formed }}{\text { no. of moles of butane consumed }}\right]
\end{aligned}
$$

\subsection{Characterisation Techniques}

Electron microscopy investigations were carried out in a Philips CM200 transmission electron microscope operated at $200 \mathrm{kV}$. The images were recorded using a Gatan Tridiem GIF. Images were analysed using the DigitalMicrograph package from Gatan Inc. The samples were lightly ground using a mortar and pestle and dispersed on a carbon-coated copper grid. Elemental mapping was carried out in the same microscope using an EDAX Genesis EDX 
detector. The elemental maps were processed using ImagePro Analyzer from Media Cybernetics Inc.

X-ray diffraction (XRD) measurements were performed in transmission mode on a STOE STADI P diffractometer equipped with a primary focusing $\mathrm{Ge}$ monochromator $\left(\mathrm{Cu} \mathrm{K} \alpha_{1}\right.$ radiation) and position sensitive detector. The samples were mounted in the form of small amounts of powder sandwiched between two layers of polyacetate film and fixed with a small amount of X-ray amorphous grease.

X-ray photoelectron spectra were measured on a Kratos Axis Ultra DLD spectrometer using monochromatised $\mathrm{Al} \mathrm{K} \alpha$ radiation and a pass energy of $40 \mathrm{eV}$. Data were analysed with CasaXPS and software developed in-house at Cardiff University.

Solid-state ${ }^{13} \mathrm{C}$ NMR was conducted on the coked catalysts using Cross Polarisation Magic Angle Spinning (CP-MAS), at a ${ }^{13} \mathrm{C}$ operating frequency of $100.65 \mathrm{MHz}$ on an $\mathrm{AV}-400$ spectrometer (Bruker). The spinning rate was $14 \mathrm{kHz}$, and a contact time of $1 \mathrm{~ms}$ and a recycle delay of 1 $\mathrm{s}$ were used. 50,000 signal scans were averaged for each sample. Spectra are referenced to a solid $\mathrm{CH}_{2}$ adamantane shift at $38.54 \mathrm{ppm}$ relative to tetramethylsilane (TMS). An exponential line broadening with a factor of $100 \mathrm{~Hz}$ was applied to all data acquired before Fourier transformation to yield the spectral data. Experimental EPR spectra were measured on a Bruker ER-200D series EPR spectrometer at room temperature in the region $200-6200 \mathrm{G}$ with a microwave frequency of $9.34 \mathrm{GHz}$ (X-band).

Carbon K-edge X-ray absorption (XAS) experiments were performed in the total electron yield mode in the in situ XPS setup of FHI at BESSY, Berlin. $\mathrm{VO}_{\mathrm{x}} / \mathrm{Al}_{2} \mathrm{O}_{3}$ samples were pressed into a pellet and the absorption of the carbonaceous material deposited as a result of the butane dehydrogenation reaction was recorded under 0.25 mbar $\mathrm{He}$ at room temperature. To correct for the absorption of carbon on the optical elements of the beamline, a reference experiment was carried out with a cleaned (carbon free) $\mathrm{Ag}$ foil sample.

For Raman spectroscopy experiments the samples were introduced into an $\mathrm{Au}$ coated stainless steel sample holder with a $0.6 \mathrm{~mm}$ deep rectangular well covering an area of $(12 \times 8) \mathrm{mm}^{2}$. Raman spectra were measured at room temperature using $514 \mathrm{~nm}$ laser excitation $(3 \mathrm{~mW})$ at $5 \mathrm{~cm}^{-1}$ spectral resolution (Kaiser Optical). Sampling times were typically $50 \mathrm{~min}$. Prior to the experiments, the Raman spectrometer was calibrated using an Ar lamp. For background subtraction the spectrum of the bare sample holder was used. The spectra were fitted with four components $(\mathrm{G}$, D, D3, and D4) [28] without the D2 band at $~ 1620 \mathrm{~cm}^{-1}$ as this band was not distinguishable from the $\mathrm{G}$ band at 1600 $\mathrm{cm}^{-1}$.

The percentage of carbon, hydrogen and nitrogen present in the catalysts was determined by microanalysis, performed by the Microanalytical Department, Department of Chemistry, University of Cambridge.

THz-TD spectra were measured on a spectrometer previously described $[29,30]$. A Femtosource Ti:sapphire laser (Femtolasers) pumped by a Millenia Xs CW laser (Spectra Physics) is used to produce 12 fs laser pulses centred at approximately $800 \mathrm{~nm}$ with a bandwidth > $100 \mathrm{~nm}$. This laser beam is then separated by a beam splitter into a pump beam and a probe beam. The pump beam is directed towards the surface of a biased GaAs semiconductor emitter, resulting in the generation of pulses of $\mathrm{THz}$ radiation of 0.3-3.5 THz. The probe beam is used for the detection of $\mathrm{THz}$ radiation. An electro-optic ZnTe crystal is employed as the detector. After homogeneously mixing the sample powder with polyethylene powder (Sigma Aldrich), the mixture was compressed into a flat-faced pellet. Polyethylene was used as a bulking agent and is transparent to $\mathrm{THz}$ radiation in the frequency range of interest. The prepared pellets were scanned one hundred times over a 13 ps time window with each scan taking approximately one minute, giving a spectral resolution of $75 \mathrm{GHz}$. Comparison of the power spectrum of the sample with that of a reference pellet containing polyethylene using the Beer-Lambert Law results in a value for the frequency-dependent absorbance of the sample [31].

\section{Results and Discussion}

\subsection{Characterisation of $\mathrm{VO}_{x} / \mathrm{Al}_{2} \mathrm{O}_{3}$}

TEM and XRD have been applied to the characterisation of the as-prepared $\mathrm{VO}_{\mathrm{x}} / \mathrm{Al}_{2} \mathrm{O}_{3}$ catalyst. Additionally, TEM has been employed to study the catalyst after calcination in oxygen prior to reaction. TEM investigation of the as-prepared sample revealed no crystalline vanadia particles. However, EDX spectroscopy revealed a vanadium content as expected from the synthesis. These observations suggest a high dispersion of vanadium in the as-prepared samples. After calcination, $\mathrm{VO}_{\mathrm{x}}$ particles of sizes below $1 \mathrm{~nm}$ are observed by TEM, but show no crystallinity. These particles are uniformly dispersed throughout the support material. To further investigate the dispersion of $\mathrm{VO}_{\mathrm{x}}$ in the sample, elemental mapping using scanning TEM (STEM) was used. Figure 1a shows a representative TEM micrograph and EDX elemental mapping images indicating the distribution of carbon, oxygen, aluminium and vanadium in the calcined catalyst particles. Figure $1 \mathrm{~b}$ shows the same data for the catalyst after reaction at $973 \mathrm{~K}$ and these data are discussed in section 3.4.2. As expected from the TEM investigations, the mapping (Figure 1a) showed a homogeneous distribution of $\mathrm{V}$ on the support material after calcination. However, the instrument resolution is insufficient to determine if $\mathrm{V}$ is present as a film or small particles. That no change is apparent in the distribution of vanadium species after calcination is important, as this process is carried out at $973 \mathrm{~K}, 10 \mathrm{~K}$ above the melting point of bulk $\mathrm{V}_{2} \mathrm{O}_{5}$. Alumina supported $\mathrm{V}_{2} \mathrm{O}_{5}$ is however, known to have different physical properties to bulk $\mathrm{V}_{2} \mathrm{O}_{5}$. For instance, TPR experiments show that the supported material undergoes reduction more easily [26]. 


\section{a) After calcination at $973 \mathrm{~K}$}
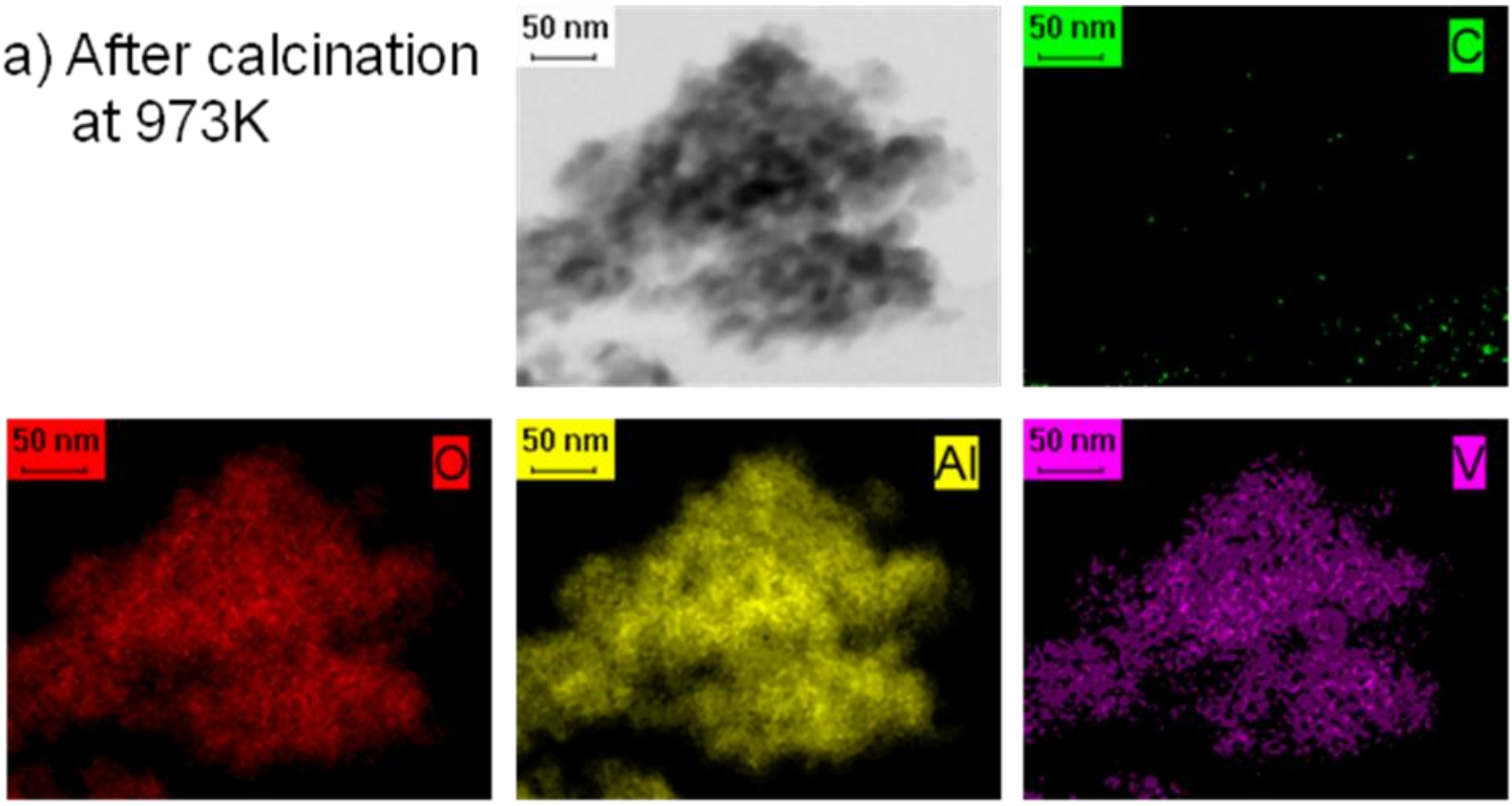

\section{b) After reaction at $973 \mathrm{~K}$}
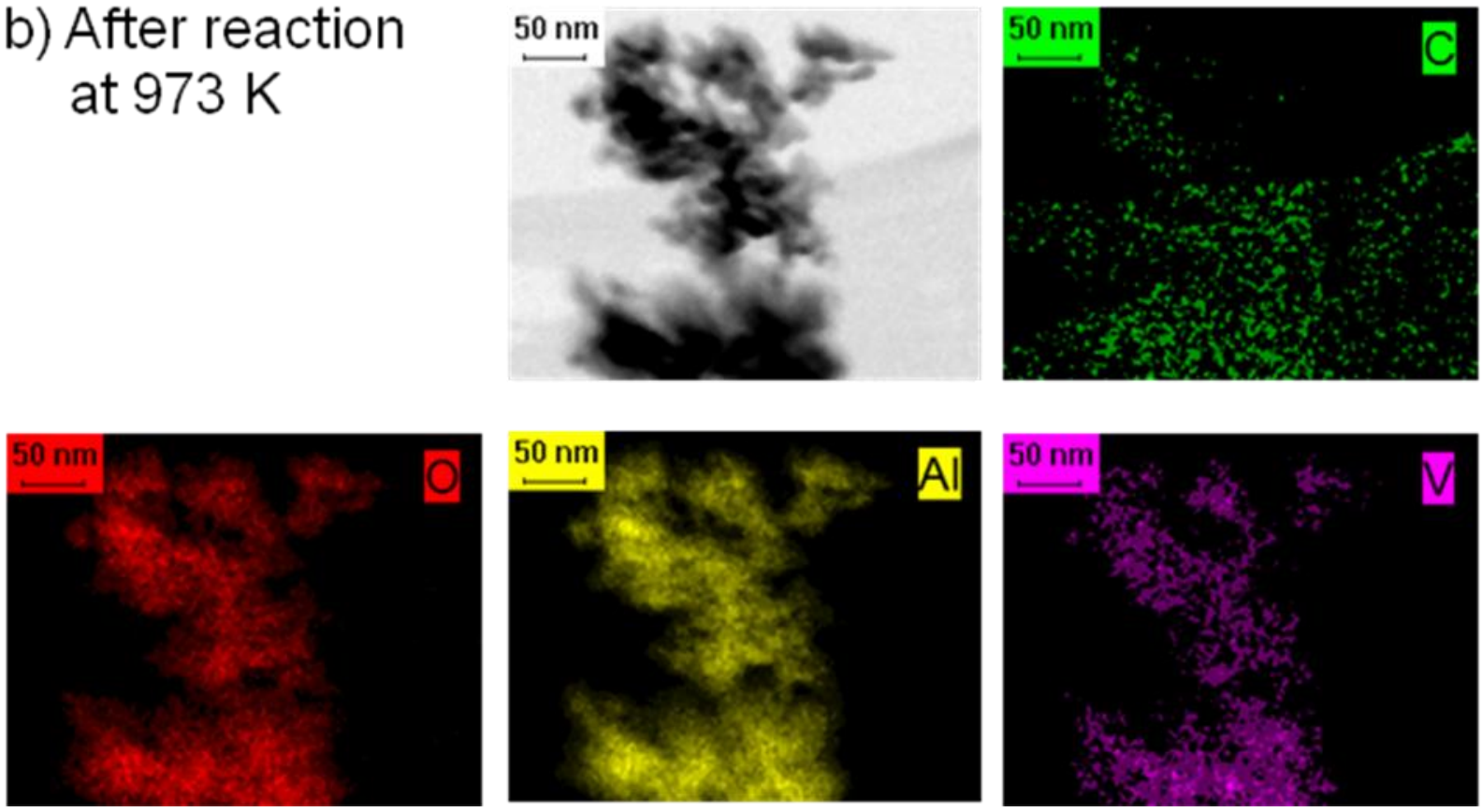

Fig. 1: a) TEM of $\mathrm{VO}_{\mathrm{x}} / \mathrm{Al}_{2} \mathrm{O}_{3}$ after calcination at $973 \mathrm{~K}$ and EDX elemental mapping images showing distribution of carbon, oxygen, aluminium and vanadium in $\mathrm{VO}_{\mathrm{x}} / \mathrm{Al}_{2} \mathrm{O}_{3}$ particles. b) TEM of $\mathrm{VO}_{\mathrm{x}} / \mathrm{Al}_{2} \mathrm{O}_{3}$ after reaction at $973 \mathrm{~K}$ and EDX elemental mapping images showing distribution of carbon, oxygen, aluminium and vanadium in $\mathrm{VO}_{\mathrm{x}} / \mathrm{Al}_{2} \mathrm{O}_{3}$ particles.

In addition to characterising the supported $\mathrm{VO}_{\mathrm{x}}$ species, XRD has been employed in order to confirm the phase of the alumina support. Rietveld fits to the acquired data were performed using the Bruker AXS software Topas, version 3.0. Employing a preferred orientation model (sixth order spherical harmonics), it was demonstrated that the majority of the crystalline fraction is $\theta-\mathrm{Al}_{2} \mathrm{O}_{3}$, however minor quantities of $\alpha-\mathrm{Al}_{2} \mathrm{O}_{3}$ are also present. This is in agreement with the previous assignment of this material as $\theta-\mathrm{Al}_{2} \mathrm{O}_{3}[3-5]$.
Previous characterisation of this catalyst has been conducted by both UV- and visible Raman spectroscopy, in addition to UV-vis spectroscopy, temperature-programmed reduction measurements, solid-state NMR and FT-IR spectroscopy [2, 3, 26, 32, 33]. These data demonstrated that the main species present on the catalyst surface were polymeric vanadates, however these co-existed with smaller quantities of both monomeric vanadates and crystalline $\mathrm{V}_{2} \mathrm{O}_{5}$-like species. Raman spectroscopy allows for the quantitative determination of the amounts of each of these 
a)

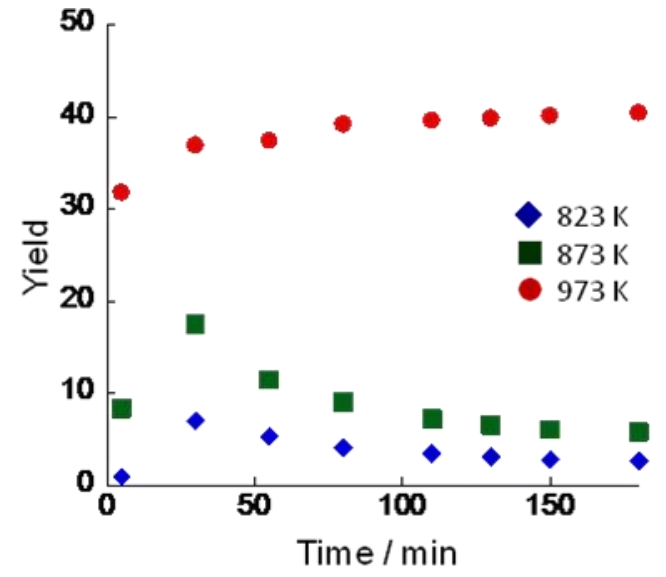

c)

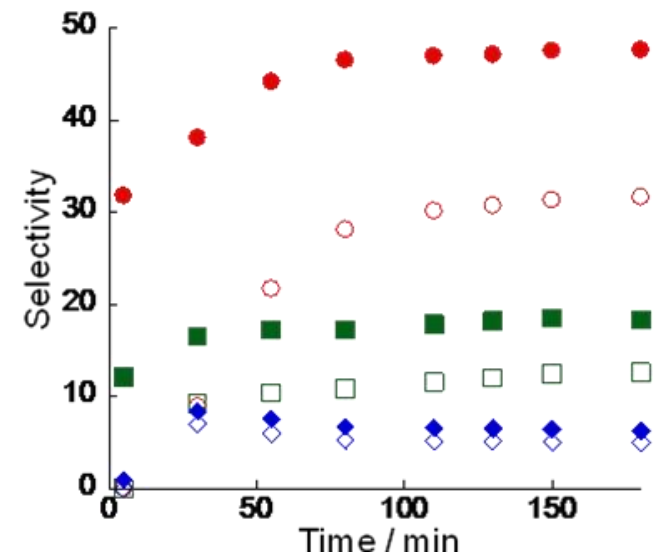

b)

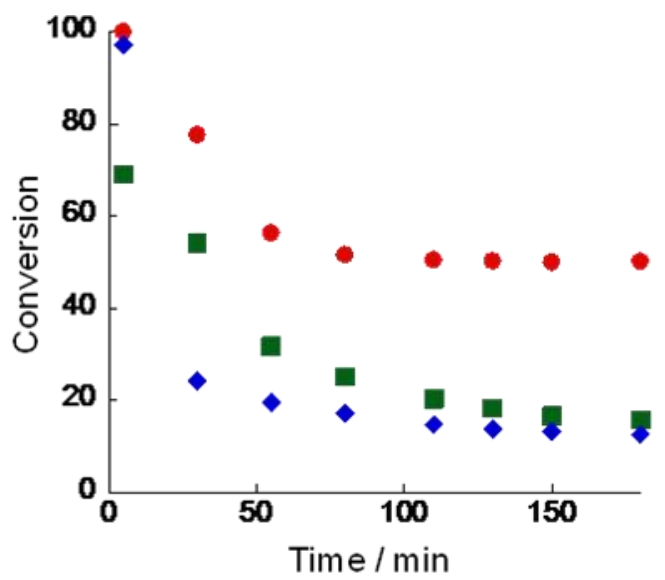

Fig. 2: a) Yield of gas-phase $\mathrm{C} 4$ products; b) conversion; c) selectivity to 1-butene (filled symbols) and 1,3-butadiene (open symbols) as a function of time-on-stream for $n$-butane dehydrogenation over $\mathrm{VO}_{\mathrm{x}} / \mathrm{Al}_{2} \mathrm{O}_{3}$ at $823(\bullet), 873(\boldsymbol{\square})$ and $973(\bullet) \mathrm{K}$.

species present [34]. In this particular case, the ratio of polymeric vanadates to monomeric species to $\mathrm{V}_{2} \mathrm{O}_{5}$ is $60: 30.2: 9.8$. That these types of vanadate species are present on alumina supported vanadia catalysts is wellestablished. A discussion of the structure of such species and their role in catalysis is provided by Weckhuysen and Keller [35].

\subsection{Catalytic Activity of $\mathrm{VO}_{x} / \mathrm{Al}_{2} \mathrm{O}_{3}$}

The catalytic performance of $\mathrm{VO}_{\mathrm{x}} / \mathrm{Al}_{2} \mathrm{O}_{3}$ has been evaluated at $723,823,873,898,923,948$ and $973 \mathrm{~K}$. The yield of $\mathrm{C}_{4}$ hydrocarbons is shown as a function of time-on-stream for a selection of these temperatures in Figure 2(a), while conversion and selectivity to 1-butene and to 1,3-butadiene are shown in Figures 2(b) and (c) respectively. It is apparent that the yield of $\mathrm{C}_{4}$ products decreases as a function of time-on-stream at $873 \mathrm{~K}$ and below, indicative of the deactivation of the catalyst. At higher temperatures however, the catalyst appears to activate with increasing exposure to the reactant and the yield increases. This difference is apparent when comparing reaction at 823 and $973 \mathrm{~K}$, with the observed yield being $40 \%$ after $180 \mathrm{~min}$ at $973 \mathrm{~K}$ but only $3 \%$ at $823 \mathrm{~K}$. Conversion and selectivity

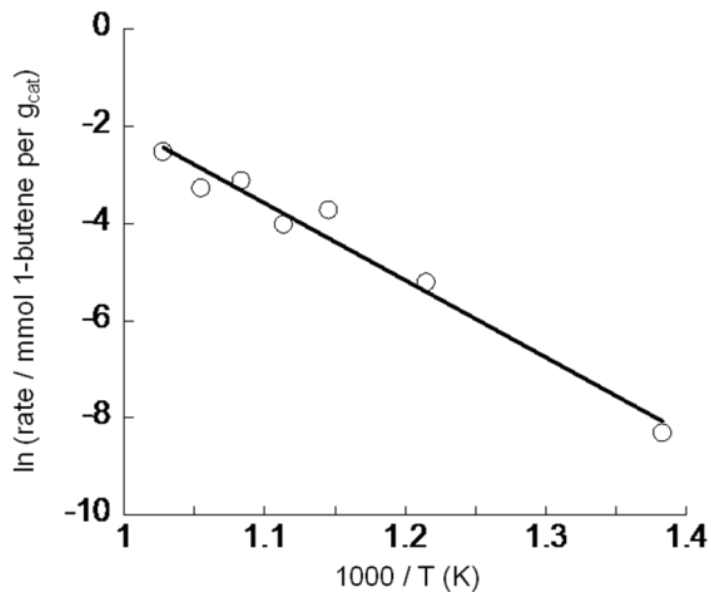

Fig. 3: Arrhenius plot of $\ln k$ (mmol 1-butene produced per $\mathrm{g}_{\text {cat }}$ ) versus $1000 / \mathrm{T}$ for $n$-butane $\mathrm{DH}$ over $\mathrm{VO}_{\mathrm{x}} / \mathrm{Al}_{2} \mathrm{O}_{3}(\mathrm{O})$. A linear relationship is observed, the gradient of which is indicative of the activation energy of the reaction, calculated as $132 \pm 10 \mathrm{~kJ} \mathrm{~mol}^{-1}$.

are also greatest at high reaction temperatures. Again comparing $823 \mathrm{~K}$ and $973 \mathrm{~K}$, conversions of $13 \%$ and 50 $\%$ respectively are achieved after $180 \mathrm{~min}$, while the selectivity to 1 -butene reaches values of $6 \%$ and $48 \%$. Butadienes are not observed as a product in the initial stages of 


\section{a)After reaction at $873 \mathrm{~K}$}
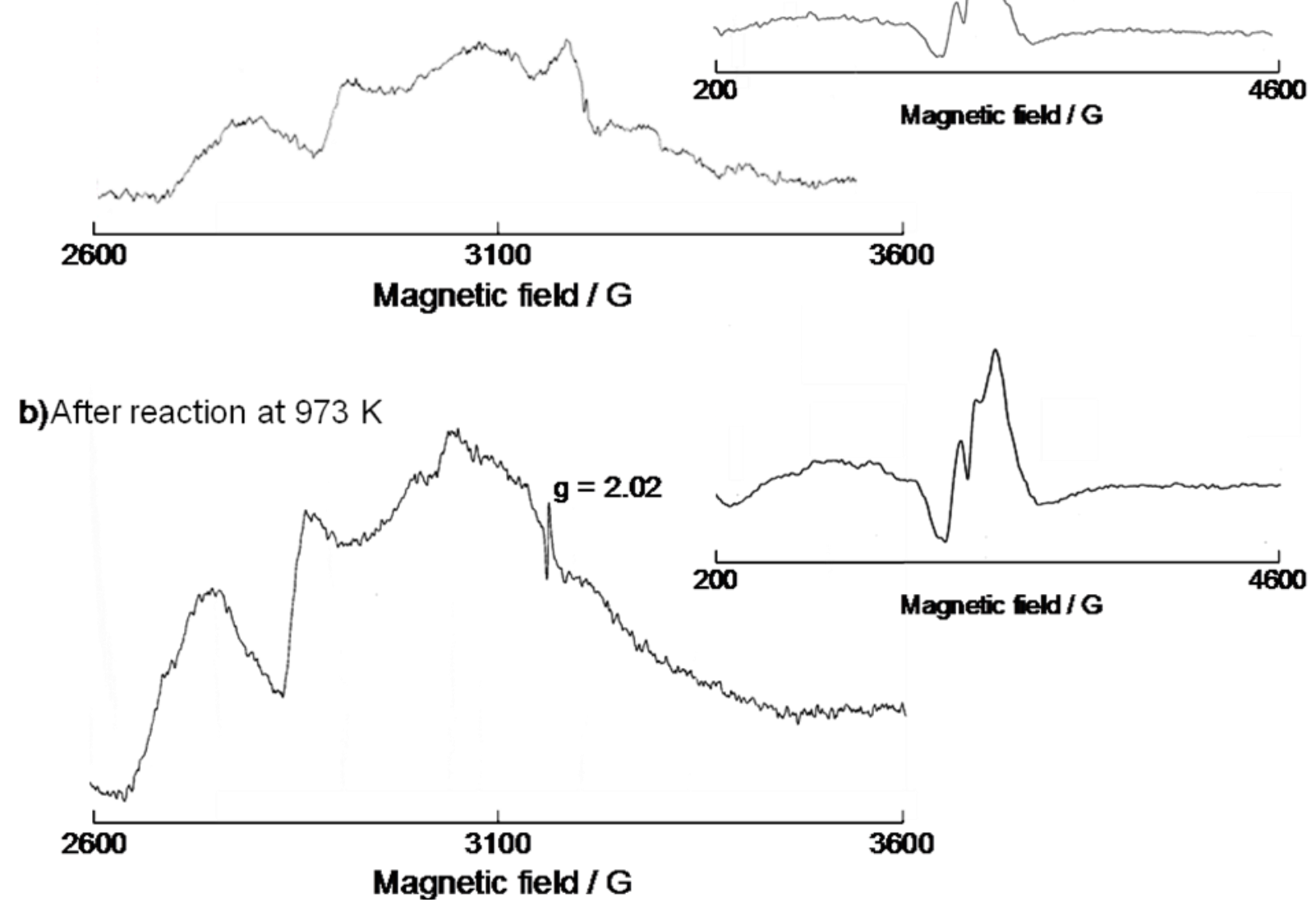

Fig. 4: a) EPR spectrum of $\mathrm{VO}_{\mathrm{x}} / \mathrm{Al}_{2} \mathrm{O}_{3}$ after reaction at $873 \mathrm{~K}$; b) EPR spectrum of $\mathrm{VO}_{\mathrm{x}} / \mathrm{Al}_{2} \mathrm{O}_{3}$ after reaction at $973 \mathrm{~K}$. The region $200-4600 \mathrm{G}$ is shown, alongside magnified images of the region $2600-3600 \mathrm{G}$ from the same spectra.

reaction. However, after $180 \mathrm{~min}$, selectivity towards $1,3-$ butadiene is comparable to that towards 1-butene with values of $5 \%$ and $32 \%$ at 823 and $973 \mathrm{~K}$. Note that the low selectivities towards $\mathrm{C}_{4}$ species at lower temperatures is due to a greater selectivity to coke deposition at this stage of the reaction. That butadiene is not produced initially may be indicative of the formation of more active dehydrogenation sites in situ as the vanadia species undergo reduction through interaction with $n$-butane and coke builds up on the surface. That the increase in butadiene production is not concomitant with a decrease in 1-butene selectivity suggests that the two products are formed from $n$-butane at different catalytic sites. Significantly, from between 80110 minutes on-stream at $973 \mathrm{~K}$, selectivity, conversion and yield all remain constant and do not deactivate with increasing exposure to $n$-butane. It is also notable that significant formation of small hydrocarbons as a result of the cracking of the feed molecule is not observed over $\mathrm{VO}_{\mathrm{X}} / \mathrm{Al}_{2} \mathrm{O}_{3}$. This may be due to the removal of acid sites on the support during the high temperature calcination step.

The activation energy for 1-butene formation has been calculated by means of an Arrhenius relationship, as shown in Figure 3. The rate of 1-butene production is cal- culated (in mmol per $\mathrm{g}_{\text {cat }}$ ) in the early stages of reaction, before significant coke forms on the catalyst surface. From these data an activation energy of $132 \pm 16 \mathrm{~kJ} \mathrm{~mol}^{-1}$ is calculated. This value is similar to values previously established for alkane dehydrogenation over supported metaloxide catalysts. For instance, Airaksinen et al. calculated activation energies in the range $132-142 \mathrm{~kJ} \mathrm{~mol}^{-1}$ for isobutene dehydrogenation over $\mathrm{CrO}_{\mathrm{x}} / \mathrm{Al}_{2} \mathrm{O}_{3}$ [36].

Additionally, the $n$-butane dehydrogenation reaction has been run at $973 \mathrm{~K}$ in an empty reactor, i.e. an identical experimental protocol to that described above was employed but no catalyst was loaded into the reactor. GC analysis confirms that no conversion of $n$-butane occurs, confirming that there is no contribution from a gas-phase, homogeneous, reaction mechanism to the results described herein in the absence of a catalyst.

\subsection{Characterisation of $\mathrm{VO}_{x} / \mathrm{Al}_{2} \mathrm{O}_{3}$ Post-Reaction}

$\mathrm{VO}_{\mathrm{x}} / \mathrm{Al}_{2} \mathrm{O}_{3}$ has also been characterised after use for the dehydrogenation of $n$-butane, at temperatures ranging from 723 to $973 \mathrm{~K}$. TEM and EPR measurements reveal the 


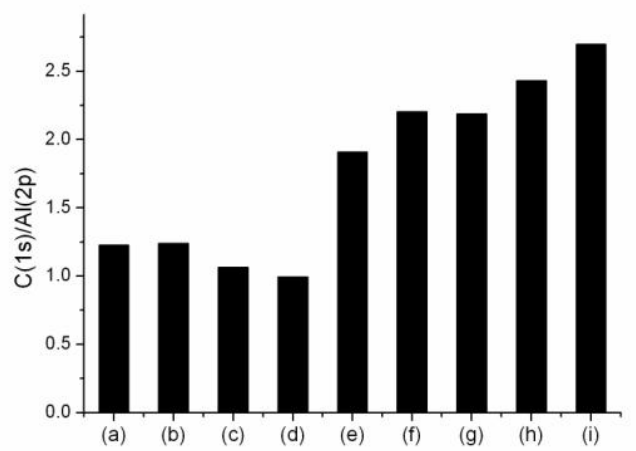

Fig. 5: XPS-derived data showing the $\mathrm{C}(1 \mathrm{~s}) / \mathrm{Al}(2 \mathrm{p})$ ratio for (a) fresh $\mathrm{VO}_{\mathrm{x}} / \mathrm{Al}_{2} \mathrm{O}_{3}$ catalyst (b) calcined at $973 \mathrm{~K}$ and after reaction with $n$-butane at (c) $723 \mathrm{~K}$ (d) $823 \mathrm{~K}$ (e) $873 \mathrm{~K}$ (f) $898 \mathrm{~K}$ (g) $923 \mathrm{~K}$ (h) $948 \mathrm{~K}$ and (i) $973 \mathrm{~K}$.

effect of reaction on the supported $\mathrm{VO}_{\mathrm{x}}$ species. Regardless of reaction temperature, TEM reveals that the catalyst showed no signs of further $\mathrm{VO}_{\mathrm{x}}$ particle formation after reaction, while elemental mapping (Figure 1) does not show any observable difference in the vanadium distribution after reaction: the elemental maps of vanadium prior to (Figure 1a) and after (Figure 1b) both show a homogeneous vanadium distribution across the entire particles.

EPR spectra of catalysts exposed to reaction at $823 \mathrm{~K}$ and $973 \mathrm{~K}$ reveal that at least some of the vanadium present has undergone reduction during reaction. Prior to reaction the vanadium is in a $5+$ oxidation state [2,3]. Figure 4 shows the room temperature X-band EPR spectra ( $v=9.34$ $\mathrm{GHz}$ ) of both samples. The spectra are rather complex, however certain features around $\mathrm{g} \sim 2$ are consistent with an axial $\mathrm{V}^{4+}$ ion with evidence of partially resolved hyperfine coupling to ${ }^{51} \mathrm{~V}(100 \% \mathrm{I}=7 / 2)$. Attempted simulation using "standard parameters" for axial $\mathrm{V}^{4+}[\mathrm{g} \leq 2.0[37,38]]$ explained many of the features in the central region but the peaks to lower field (an intense peak at ca. $2700 \mathrm{G}$ ) and an additional "half-field" feature around $1450 \mathrm{G}$ are not consistent with the presence of an isolated $\mathrm{V}^{4+}$ ion. Indeed the half-field feature is consistent with the presence of lower oxidation state $\mathrm{V}$ species such as $\mathrm{V}^{3+}$ [39]. Vanadia based catalysts are well known to undergo reduction during dehydrogenation and oxidative dehydrogenation reactions $[5,9$, 40]. That reduced species are present after $n$-butane dehydrogenation over the catalyst employed in the present work is supported by in situ XPS and NEXAFS studies which show the average oxidation state of vanadium to be $3.5+[7$, 41]. EPR spectroscopy results are therefore in agreement with these data.

\subsection{Carbon Deposits}

The chemical nature of carbonaceous material deposited on $\mathrm{VO}_{\mathrm{x}} / \mathrm{Al}_{2} \mathrm{O}_{3}$ during $n$-butane dehydrogenation reactions at temperatures of $873 \mathrm{~K}$ and below has been the subject of previous investigations. Wu and Stair have demonstrated that two-dimensional networks of polyaromatic hydrocarbons form in the presence of polymeric $\mathrm{VO}_{\mathrm{x}}$ species. Such species are the dominant species on the surface of the catalyst employed herein [5]. Furthermore, the mechanism of the formation of such coke has been postulated to proceed via a polystyrene like intermediate [3]. More recent studies have suggested that these large polyaromatic networks play only a minor role in catalyst deactivation during $n$-butane dehydrogenation [4]. It is likely that the precise role that these deposits play is heavily influenced by reaction conditions. In the present study the quantity of coke formed is probed by XPS, elemental microanalysis and ${ }^{13} \mathrm{C}$ CP-MAS NMR spectroscopy. NMR and TEM alongside THz-TDS, XAS, Raman and EPR spectroscopies provide additional insights into the nature of the deposited material. These techniques show that as the reaction temperature increases more ordered carbon deposits are formed. Further, we propose that these structures may have a distinct catalytic function.

\subsubsection{Quantification of coke}

XPS studies, conducted ex situ, provide information on the quantity of carbonaceous material present. Figure 5 shows the variation in the $\mathrm{C}(1 \mathrm{~s}) / \mathrm{Al}(2 \mathrm{p})$ intensity ratio as a function of reaction temperature as well as for both asprepared $\mathrm{VO}_{\mathrm{x}} / \mathrm{Al}_{2} \mathrm{O}_{3}$ and $\mathrm{VO}_{\mathrm{x}} / \mathrm{Al}_{2} \mathrm{O}_{3}$ after calcination at $973 \mathrm{~K}$. These data show a clear and sudden increase in coke formation at $873 \mathrm{~K}$, with a continuous increase in carbon coverage in the temperature range $873 \mathrm{~K}$ to $973 \mathrm{~K}$. Information on the quantity of coke deposited is also provided by microanalysis measurements (Table 1). As can be seen, the quantity of hydrocarbonaceous material increases as a function of reaction temperature, confirming the results of the XPS study. At a reaction temperature of $723 \mathrm{~K}$ only $2.0 \%$ of the used catalyst by mass is carbon and hydrogen; however, at $973 \mathrm{~K}$ this rises to $7.4 \%$. In addition to information on the quantity of carbon present these data also provide insights into the nature of the coke. In particular the degree of aromaticity is indicated through inspection of the $\mathrm{C} / \mathrm{H}$ ratio, also shown in Table 1 . A higher $\mathrm{C} / \mathrm{H}$ ratio suggests that the coke present is more aromatic in nature. As expected, as the reaction temperature increases the coke becomes increasingly aromatic with a $\mathrm{C} / \mathrm{H}$ mole ratio of 2.6 at $973 \mathrm{~K}$ as compared to only 0.4 at $723 \mathrm{~K}$.

Table 1. Elemental microanalysis data showing wt. \% carbon and hydrogen and the $\mathrm{C} / \mathrm{H}$ mole ratio after $180 \mathrm{~min}$ of reaction over $\mathrm{VO}_{\mathrm{x}} / \mathrm{Al}_{2} \mathrm{O}_{3}$.

\begin{tabular}{llll}
\hline Catalyst & Reaction temperature $(\mathrm{K})$ & wt. $\%(\mathrm{C}+\mathrm{H})$ & $\mathrm{C} / \mathrm{H}$ mole ratio \\
\hline $\mathrm{VO}_{x} / \mathrm{Al}_{2} \mathrm{O}_{3}$ & 723 & 2.0 & 0.4 \\
& 823 & 3.1 & 0.7 \\
& 873 & 5.1 & 1.6 \\
& 898 & 5.4 & 1.5 \\
& 923 & 6.6 & 2.0 \\
& 948 & 7.2 & 1.9 \\
& 973 & 7.4 & 2.6 \\
\hline
\end{tabular}


a)

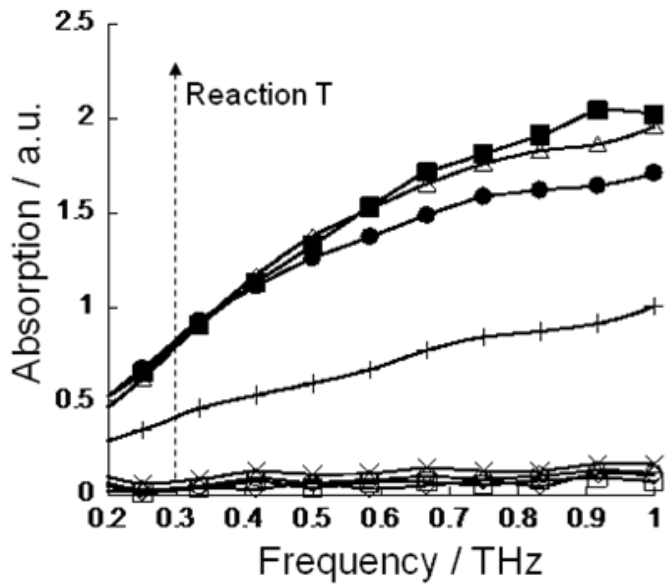

c)

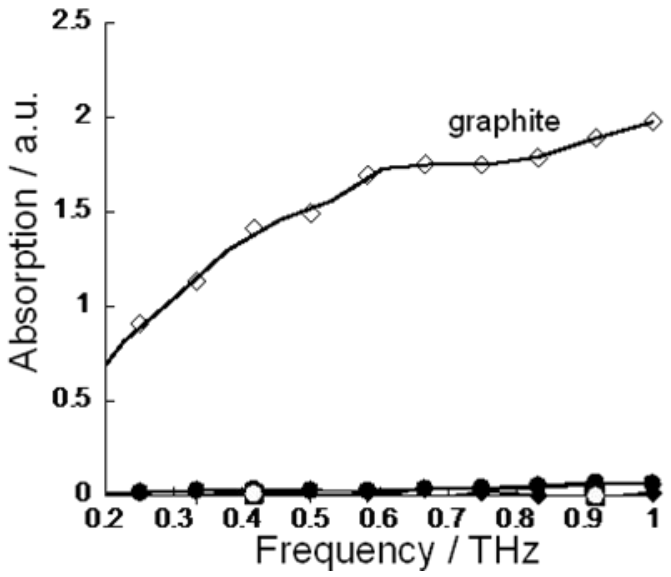

b)

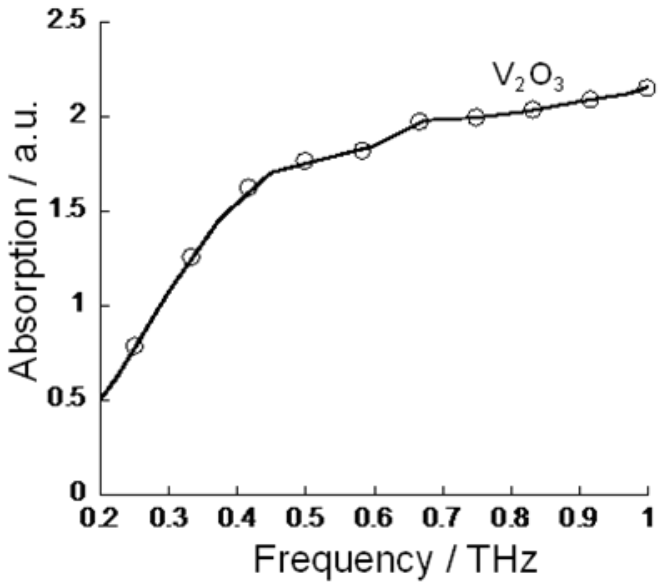

Fig. 6: a) THz-TD spectra of $\mathrm{VO}_{\mathrm{x}} / \mathrm{Al}_{2} \mathrm{O}_{3}$ employed in the dehydrogenation of $n$-butane for a time-on-stream of 180 min at $723(\square), 823(\diamond), 873$ $(\times), 898(+), 923(\bullet), 948(\triangle)$ and $973 \mathrm{~K}(\mathbf{\square})$. The calcined catalyst prior to reaction is also shown $(\mathrm{O})$. b) THz-TD spectra of $\mathrm{V}_{2} \mathrm{O}_{3}(\mathrm{O})$; c) THz-TD spectra of phenanthrene $(\square)$, anthracene $(+)$, 2,3-benzanthracene $(\bullet)$, 1,2-benzanthracene $(\bullet)$, triphenylene $(\mathbf{a})$, chrysene $(\boldsymbol{\nabla})$, coronene $(-)$ and graphite $(\diamond)$.

These data are further supported by GC analyses which show that not all of the $n$-butane consumed is transformed into gas-phase reaction products detectable by FID. Based on a simple mass balance, assuming that all of the unaccounted for material is transformed into retained carbon, it is possible to infer selectivity to coke formation from the data presented in Figure 2. Perhaps surprisingly, it is at the highest reaction temperature that selectivity to coke is lowest. After $180 \mathrm{~min}$ on stream the calculated selectivity is $19 \%$ at $973 \mathrm{~K}$ as opposed to $62 \%$ at $823 \mathrm{~K}$. It should be noted that conversion of $n$-butane is significantly higher at $973 \mathrm{~K}$, thus these selectivities are consistent with the greater quantity of carbon retained on the catalyst at higher temperatures.

\subsubsection{Nature of coke}

\section{THz Time-Domain Spectroscopy}

The nature of the coke deposited during reaction has been probed in detail by THz-TDS and TEM, while XAS, NMR, EPR and Raman spectroscopies provide additional insights. Figure 6(a) shows the THz-TD spectra of
$\mathrm{VO}_{\mathrm{x}} / \mathrm{Al}_{2} \mathrm{O}_{3}$ after calcination at $973 \mathrm{~K}$ but prior to reaction, and after reaction at temperatures from 723 to $973 \mathrm{~K}$. For both the unreacted catalyst, and those exposed to $n$-butane at 723,823 and $873 \mathrm{~K}$, the absorption of $\mathrm{THz}$ radiation is low. For reaction temperatures in excess of $873 \mathrm{~K}$ however, a dramatic increase in absorption is observed. This suggests that the nature of the deposited coke changes above this temperature. A second possibility is that the high absorption arises from the formation of reduced $\mathrm{VO}_{\mathrm{x}}$ species. For instance, both bulk $\mathrm{V}_{2} \mathrm{O}_{3}$ and $\mathrm{V}_{6} \mathrm{O}_{13}$, which are formed by the reduction of bulk $\mathrm{V}_{2} \mathrm{O}_{5}$, are conductive at room temperature $[42,43]$. In order to confirm that the increase in $\mathrm{THz}$ absorption is due to carbonaceous deposits and not reduced vanadate species, THz-TD spectra of $\mathrm{VO}_{\mathrm{x}} / \mathrm{Al}_{2} \mathrm{O}_{3}$ reduced in hydrogen at $973 \mathrm{~K}$ and $1273 \mathrm{~K}$ after calcination were acquired. Wu et al. have previously demonstrated that reduction of $\mathrm{VO}_{\mathrm{x}} / \mathrm{Al}_{2} \mathrm{O}_{3}$ is achieved at 783-803 $\mathrm{K}$ [26]. No detectable difference was observed between the THz-TD spectra of the calcined and the reduced samples. The THzTD spectrum of bulk $\mathrm{V}_{2} \mathrm{O}_{3}$ was also acquired and is presented in Figure 6(b). In contrast to reduced $\mathrm{VO}_{\mathrm{x}} / \mathrm{Al}_{2} \mathrm{O}_{3}$, this material shows strong $\mathrm{THz}$ absorption, due to the presence of a long-range conductive network, absent in supported nanoparticles. The transition observed above $823 \mathrm{~K}$ 
in the THz-TD spectra in Figure 6(a) can therefore be assigned to a change in the nature of the carbonaceous deposits. This closely corresponds to the temperature at which a sudden increase in the quantity of deposited coke is observed by XPS (Figure 5) and is supported by elemental microanalysis data (Table 1). Two distinct regimes can hence be identified: a high reaction temperature regime where coke absorbs $\mathrm{THz}$ radiation strongly; and a low reaction temperature regime where only weak absorption occurs. These regimes are clearly distinguished between by THz-TDS measurements.

THz-TDS has previously been employed in the study of carbonaceous materials, in particular CNTs and carbon nanofibres (CNFs) [30, 44-46]. However, no prior THzTDS characterisation of coke deposited during a catalytic reaction has previously been reported. Studies on nanostructured carbons have clearly demonstrated a direct correlation between the degree of graphitic order of a material and absorption coefficient in THz-TD spectra. In particular, a higher absorption coefficient has been shown to be associated with higher mobile electron density and a more substantial region of graphene-like order, with fewer terminations [30, 44]. The ability of THz-TDS to discriminate between such materials arises from its sensitivity to medium-range interactions such as phonon modes and other lattice dynamics interactions. It is not however inherently obvious how extensive a graphitic network is required before carbonaceous material exhibits the high absorption that is characteristic of coke deposited at high reaction temperatures. In an attempt to address this, a number of model coke compounds have been investigated by THzTDS. Figure 6(c) shows THz-TD spectra of phenanthrene, anthracene, 2,3-benzanthracene, 1,2-benzanthracene, triphenylene, chrysene and coronene and graphite. All "molecular" species (i.e. all the model coke compounds bar graphite) show similar, low, THz absorption. Only graphite absorbs $\mathrm{THz}$ radiation strongly, in a similar manner to nanostructured carbons reported previously [30, 44-46]. The low absorption by the molecular aromatic species is similar to the $\mathrm{THz}$ spectra observed for $\mathrm{VO}_{\mathrm{X}} / \mathrm{Al}_{2} \mathrm{O}_{3}$ after reaction at temperatures of $873 \mathrm{~K}$ or below. This suggests a structural similarity between coke formed at these conditions and these simple aromatic compounds. In these systems, the electrons within the aromatic rings can move only within discrete molecules, and the extensive aromatic networks present in nanostructured carbons are not present. Conversely, above a reaction temperature of $873 \mathrm{~K}$ the $\mathrm{THz}$-TD spectra of $\mathrm{VO}_{\mathrm{x}} / \mathrm{Al}_{2} \mathrm{O}_{3}$ resemble those of polyaromatic species consisting of an extended two-dimensional sheet structure, such as graphite. The strong absorption shown by graphite is predominately due to the presence of conducting free electrons and phonon mode contributions. The increase in absorption with increasing reaction temperature observed in the present work for carbon deposits on $\mathrm{VO}_{\mathrm{x}} / \mathrm{Al}_{2} \mathrm{O}_{3}$ is therefore a reflection of the increasing graphitic order of the coke, and the larger network size of such deposits. While the minimum size of the graphitic network required for $\mathrm{THz}$ radiation to be strongly absorbed has not been identified, it is apparent that it must be greater than that present in coronene, the largest of the model coke compounds studied. Coronene contains seven fused benzene rings and has a molecular diameter of $0.9 \mathrm{~nm}$.

\section{Other Techniques}

Further to analysis by THz-TDS, changes in the electronic nature of the coke at different reaction temperatures are also revealed by ${ }^{13} \mathrm{C}$ CP-MAS NMR and EPR spectroscopies, while the increasing order (and therefore increasing $\mathrm{C} / \mathrm{H}$ ratio) is confirmed through XPS, Raman spectroscopy, elemental microanalysis and TEM, vide infra.

Figure 7 shows ${ }^{13} \mathrm{C}$ CP-MAS NMR spectra obtained from $\mathrm{VO}_{\mathrm{x}} / \mathrm{Al}_{2} \mathrm{O}_{3}$ after reaction at $723,823,873$ and $973 \mathrm{~K}$. The resonance centred at $\sim 130 \mathrm{ppm}$ is associated with carbon nuclei in either aromatic or polyolefinic environments [47]. If present, carbon in aliphatic environments would appear at around $30 \mathrm{ppm}$, and is observed only after reaction at 723 and $823 \mathrm{~K}$. Comparing the sample reacted at $723 \mathrm{~K}$ to that reacted at $823 \mathrm{~K}$ it is apparent that the higher reaction temperature results in a $130 \mathrm{ppm}$ peak of greater intensity, corresponding to a greater quantity of carbonaceous material, in agreement with XPS and elemental analysis results. The catalysts reacted at $873 \mathrm{~K}$ and 973 $\mathrm{K}$ do not however produce an observable NMR spectrum. The loss of NMR signal associated with coked material is well known. For example, similar results have previously been observed by Richardson and Haw investigating coke deposited on HY zeolites, during reactions of butadiene, by ${ }^{13} \mathrm{C}$ CP-MAS NMR in which a loss in NMR signal intensity was observed at high reaction temperatures [48]. This loss in signal correlates primarily with the presence of organic radicals, and also with a deficiency of hydrogen nuclei in
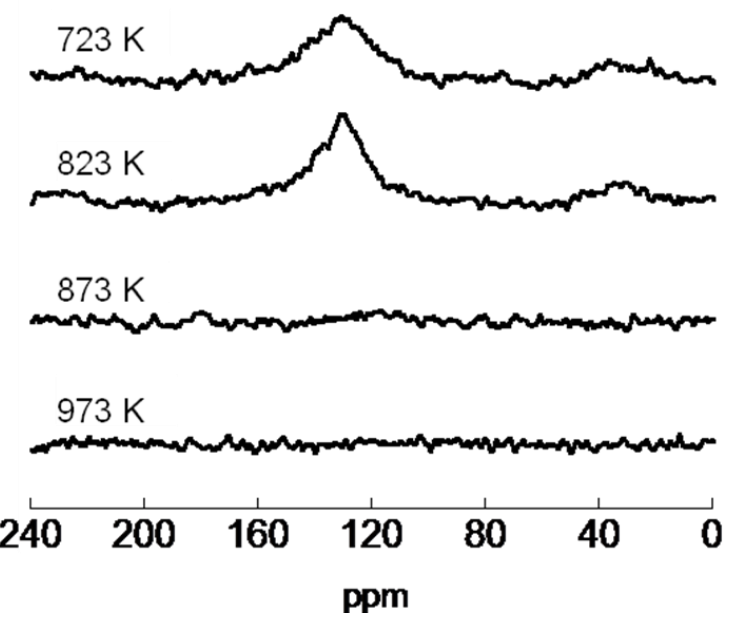

Fig. 7: ${ }^{13} \mathrm{C}$ CP-MAS NMR spectra of $\mathrm{VO}_{\mathrm{x}} / \mathrm{Al}_{2} \mathrm{O}_{3}$ employed in the dehydrogenation of $n$-butane at various reaction temperatures for a time-on-stream of $180 \mathrm{~min}$ 
regions of highly ordered carbon [49]. Similarly, Meinhold and Bibby observed a loss of NMR signal from coke derived from the conversion of methanol over H-ZSM-5 [50]. This was assigned to the formation of conducting ordered coke structures on the catalyst surface detuning the NMR probe. The NMR probe is similarly detuned in the present study. The deposited carbon can therefore be considered conducting in nature and as such highly ordered, in agreement with THz-TDS studies.

Further support for the hypothesis that organic radicals are present in the deposited carbon is provided by EPR spectroscopy (Figure 4). A sharp resonance at $\mathrm{g} \sim 2.02$ is clearly observable in the sample reacted at $973 \mathrm{~K}$, however only a very small quantity is present in that reacted at 823 $\mathrm{K}$. This signal most likely arises from the presence of organic radicals in the coke deposited at high reaction temperature, the g-factor being consistent with previous observations of such species [21, 51]. An EPR resonance has also been observed at this value for MWCNTs [52, 53]. This was assigned to the presence of holes in the pristine nanotubes. Gas-phase radical formation is also possible under high-temperature conditions in the presence of an appropriate catalyst [54].

The increased order of the coke deposited in the high-temperature regime is confirmed by further spectroscopic analyses. XAS spectra of reacted catalysts reveal differences between cokes deposited at different temperatures. Figure 8 depicts the carbon K-edge spectrum of the representative samples from the two regimes: 823 and 973 $\mathrm{K}$. The absorption spectrum can be subdivided into three regions, characterized by specific resonances. The dominating $\pi^{*}$ resonance at $285.5 \mathrm{eV}$ corresponds to the transition of $1 \mathrm{~s}$ electrons to a $\pi^{*}$ antibonding orbital indicating the presence of unsaturation ( $\pi$-bonding) in the carbonaceous deposit. Valence C-H related transitions occupy the region of $287-290 \mathrm{eV}$. The intensity of these transitions is reduced for the sample reacted at $973 \mathrm{~K}$, suggesting a lower hydrogen content of the sample, in agreement with the results of microanalysis, Table 1 . The third region above the ionization potential is associated with $\sigma^{*}$ shape resonances. The small hatched "peak" in the $973 \mathrm{~K}$ sample is typical for graphitic samples, indicating a degree of ordering of the carbonaceous material. XAS measurements therefore reveal a higher $\mathrm{C} / \mathrm{H}$ ratio and greater ordering of the coke deposited on $\mathrm{VO}_{\mathrm{X}} / \mathrm{Al}_{2} \mathrm{O}_{3}$ at $973 \mathrm{~K}$ as compared to $823 \mathrm{~K}$.

Raman spectroscopy is widely used to investigate carbonaceous materials with different degrees of (dis)order [5, 55-57]. However, in the present study it does not yield unambiguous results. The most characteristic part of the Raman spectrum is the $1700-1000 \mathrm{~cm}^{-1}$ region with the $\mathrm{G}$ band at around $1580 \mathrm{~cm}^{-1}$ associated with the $\mathrm{E}_{2 \mathrm{~g}}$ optical mode of graphite or $\mathrm{sp}^{2}$ carbon materials and the $\mathrm{D}$ band(s) at $\sim 1350 \mathrm{~cm}^{-1}$ corresponding to disorder-allowed vibration modes. Figure 9 shows the region of $\mathrm{D}$ and $\mathrm{G}$ vibrations for representative $\mathrm{VO}_{\mathrm{x}} / \mathrm{Al}_{2} \mathrm{O}_{3}$ samples. The spectra were fitted with four components (G, D1, D3, and D4), which have been described previously [28]. Note that we have not in

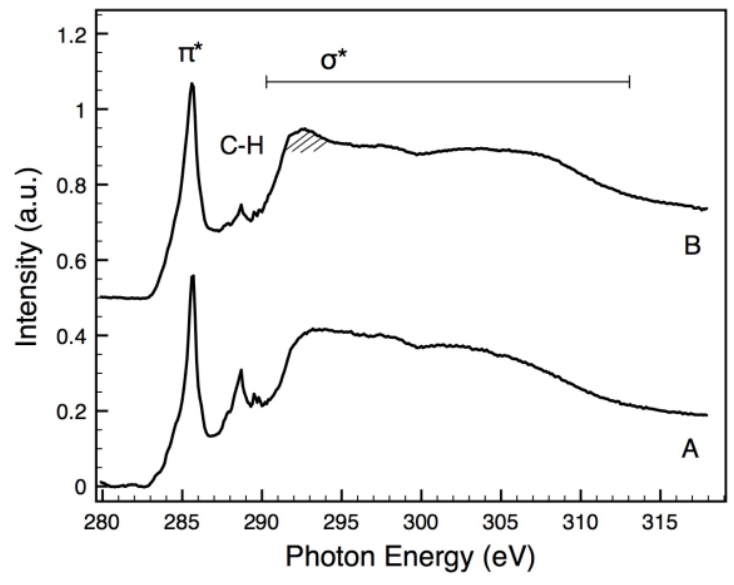

Fig. 8: Carbon K-edge X-ray absorption spectra of $\mathrm{VO}_{\mathrm{x}} / \mathrm{Al}_{2} \mathrm{O}_{3}$ employed in the dehydrogenation of $n$-butane at reaction temperatures of 823 (a) and $973 \mathrm{~K}$ (b) for a time-on-stream of $180 \mathrm{~min}$. Spectra have been recorded in $\mathrm{He}$ at room temperature.

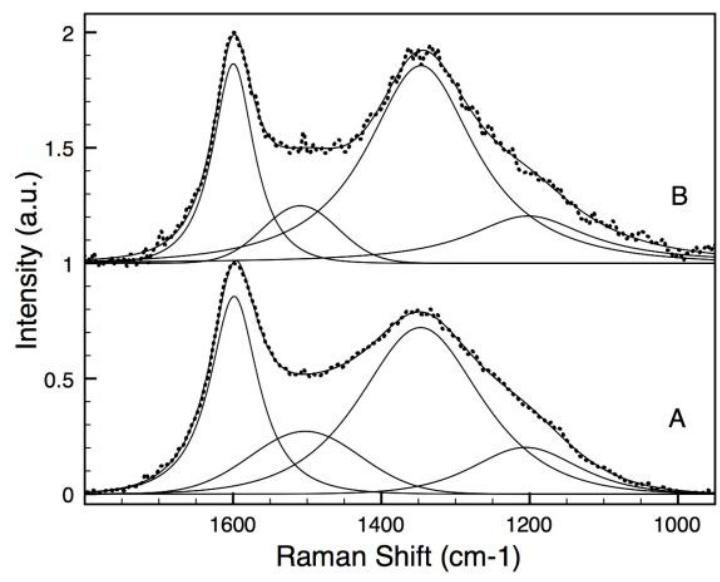

Fig. 9: Part of the Raman spectra of $\mathrm{VO}_{\mathrm{x}} / \mathrm{Al}_{2} \mathrm{O}_{3}$ employed in the dehydrogenation of $n$-butane at reaction temperatures of 823 (a) and $973 \mathrm{~K} \mathrm{(b)}$ for a time-on-stream of $180 \mathrm{~min}$. The position of the $\mathrm{G}$ and $\mathrm{D}$ bands employed in the fitting [28] are indicated.

troduced into the fitting procedure the band D2 at around $1620 \mathrm{~cm}^{-1}$ as there is no clear indication of two peaks around the $\mathrm{G}$ band in the recorded spectra. There are only small differences between the two spectra. The most obvious is that after reaction at lower temperature the G and D bands are less separated, the bands are broader and the D3 band at $\sim 1500 \mathrm{~cm}^{-1}$ is better resolved. There is no significant difference in the intensity ratio D-to-G and their positions are fairly constant. Since perfect graphite exhibits only the $\mathrm{G}$ band, this ratio is considered as a good measure of the degree of disorder. However, Raman active vibrations in the region of the $\mathrm{G}$ band have been observed for benzene, indicating that this band alone cannot prove the existence of a high degree of order in carbonaceous materials [57]. Furthermore, disordered and amorphous materials exhibit much broader bands than ordered materials and the best parameter (i.e. band position, full width at half maxi 
a) $823 \mathrm{~K}$

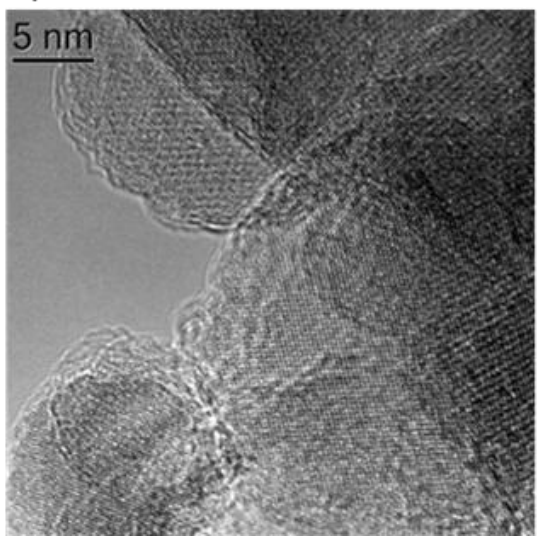

b) $973 \mathrm{~K}$

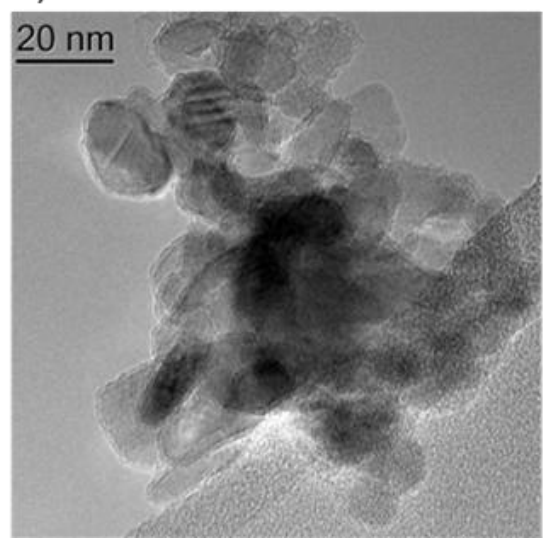

c) $973 \mathrm{~K}$

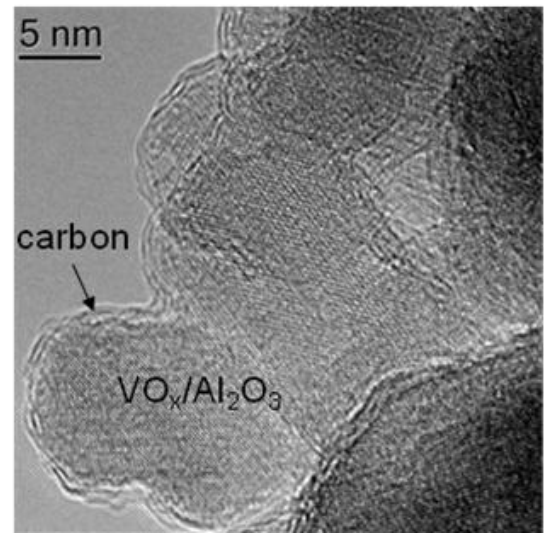

Fig. 10: Transmission electron micrographs of $\mathrm{VO}_{\mathrm{x}} / \mathrm{Al}_{2} \mathrm{O}_{3}$ after reaction at $823 \mathrm{~K}$ (a) and $973 \mathrm{~K}$ (b) and (c). (a) and (c) show high magnification images revealing the nature of the deposited carbon while (b) shows that at high temperature coke encapsulates agglomerates of catalyst particles.

mum or intensity ratio) to reveal the degree of (dis)order is still not fully clear. While the results of Raman spectroscopy investigations are inconclusive in isolation, combined with the data acquired through other techniques the somewhat narrower D and G bands of the sample reacted at 973 $\mathrm{K}$ are clearly consistent with an increase in graphitic character of the samples.

This increase in the degree of graphitisation is further supported by TEM data. After reaction, carbonaceous material was observed covering the support particles regardless of reaction temperature. Samples reacted at $823 \mathrm{~K}$ show a carbonaceous surface layer consisting of plate-like carbon following the surface of the $\mathrm{Al}_{2} \mathrm{O}_{3}$ support particles (Figure 10a). The individual platelets are rarely more than $5 \mathrm{~nm}$ long. This surface layer is incomplete, varying from $\sim 0$ to 3 layers of carbon and covers mainly individual support particles. A few particles consisting of pure carbon were also observed. For the samples reacted at $973 \mathrm{~K}$ (Figure $10 \mathrm{~b}, \mathrm{c})$, a similar surface covering is observed. However, in these cases the support particles were completely coated by a carbon layer continuously covering several support particles. The resultant carbon platelets, which are around an order of magnitude greater in length and more regular in nature than after reaction at $823 \mathrm{~K}$, can be followed for several tens of nanometres without any signs of discontinuities at the support particle boundaries. The platelets even closely follow the valleys where support particles connect and lower magnification images reveal that support particle agglomerates are completely encapsulated in carbon, Figure 10b. Therefore, after reaction at $973 \mathrm{~K}$ it appears that the deposited carbonaceous layer completely covers the surface, encapsulating catalyst particles. As a result no accessible vanadia centres are available to reactant molecules upon the formation of this layer. These conclusions are based on an analysis of $>30$ micrographs per sample, of which those in Figure 10 are representative examples. The elemental map of carbon (Figure 1b) further substantiates the TEM observation of a uniform carbon layer. Additionally, UV-vis spectroscopy studies of the catalyst after reaction at $973 \mathrm{~K}$ (not shown) do not present any peaks characteristic of vanadia of units.

In summary, the nature of the carbonaceous material deposited on $\mathrm{VO}_{\mathrm{x}} / \mathrm{Al}_{2} \mathrm{O}_{3}$ during $n$-butane dehydrogenation shows a strong dependence on reaction temperature. At high reaction temperatures highly ordered, conducting networks of polyaromatic hydrocarbons encapsulate the catalyst particle. At low reaction temperatures the coke is much less ordered in nature, consisting of discrete molecular units with substantial areas of the catalyst surface left exposed and available for reaction.

\subsubsection{Activity of Coke Deposits on $\mathrm{VO}_{x} / \mathrm{Al}_{2} \mathrm{O}_{3}$}

Spectroscopic and microscopic techniques have identified two distinct categories of coke deposit over $\mathrm{VO}_{\mathrm{x}} / \mathrm{Al}_{2} \mathrm{O}_{3}$, as described above. At low reaction temperatures, e.g. $823 \mathrm{~K}$, the coke is poorly ordered and not present as an extended, graphene-like network. At high reaction temperatures, e.g. $973 \mathrm{~K}$, much more extensive and highly ordered coke is deposited. Relating the catalyst activity, shown in Figure 2, to the nature of the coke, clear trends are apparent. In the low temperature regime, where the coke consists of discrete molecular units and more amorphous carbon, the catalyst deactivates with time-on-stream with both yield and conversion decreasing. Selectivity towards 1-butene and 1,3-butadiene remains fairly constant throughout. This suggests that the reaction mechanism is relatively unaffected by coke deposition, and therefore that the bulk of catalytic activity is at all times provided by sites present at the start of the reaction, namely $\mathrm{VO}_{\mathrm{x}}$ units on the alumina surface. In the high temperature regime, where the coke consists of more extended, ordered carbon networks, very different catalytic behaviour is observed. The calculated yield increases as a function of time-on-stream, indicating activation of the catalyst as coke is deposited. 
Furthermore, after a short induction period, conversion reaches a constant value. Both of these factors demonstrate that the $\mathrm{VO}_{\mathrm{x}} / \mathrm{Al}_{2} \mathrm{O}_{3}$ catalyst does not suffer from deactivation at high reaction temperatures, despite a greater quantity of coke being present as compared to low reaction temperatures. Selectivity to the dehydrogenation products shows a more marked dependence on time-on-stream than at low temperatures. For example, selectivity to 1-butene increases from an initial value of $32 \%$ to a steady-state value of $48 \%$. This steady-state value is achieved around the same time as conversion reaches steady-state at $50 \%$. A notable decrease in selectivity towards carbon deposition from $66 \%$ to $20 \%$ occurs over the same period. These changes are perhaps indicative of a change in the reaction mechanism, and in the nature of the catalytically active site.

That a change in the catalytically active site has occurred is confirmed by TEM data, which show that the $\mathrm{VO}_{\mathrm{x}} / \mathrm{Al}_{2} \mathrm{O}_{3}$ catalyst particles are encapsulated in carbon after reaction at $973 \mathrm{~K}$. As such, any $\mathrm{VO}_{\mathrm{x}}$ sites will be rendered inaccessible to $n$-butane molecules. Despite this, the catalyst remains highly active, even after $180 \mathrm{~min}$ on stream. Indeed the yield of $\mathrm{C}_{4}$ hydrocarbons reaches its greatest value $(40 \%)$ at this time. The initial carbon deposits are most likely formed through the catalytic action of $\mathrm{VO}_{\mathrm{x}}$ units breaking down butane molecules. However, after $180 \mathrm{~min}$ on stream the carbonaceous material has a thickness of multiple layers, despite the inaccessible nature of the original catalyst. Further carbon formation therefore appears to have taken place upon the deposits. These data therefore suggest the possibility that catalytic activity is provided by the carbonaceous deposits themselves. TEM data presented in section 3.4.2 revealed significant structural similarities between carbonaceous material deposited at high temperature over $\mathrm{VO}_{\mathrm{x}} / \mathrm{Al}_{2} \mathrm{O}_{3}$ and nanostructured carbons, such as CNFs. Notably, the deposited coke (Figure 10) can be characterised as curved "graphene-like" sheets. CNFs can be considered as graphene sheets formed into conical sections [27]. As a consequence of this apparent structural similarity between high-temperature coke deposits and CNFs it was decided to study the activity of CNFs towards $n$-butane DH. Table 2 compares the selectivity and conversion of $\mathrm{VO}_{\mathrm{x}} / \mathrm{Al}_{2} \mathrm{O}_{3}$ and the CNFs at a reaction temperature of $973 \mathrm{~K}$. After the initial induction period, during which coke is deposited on the surface of $\mathrm{VO}_{\mathrm{x}} / \mathrm{Al}_{2} \mathrm{O}_{3}$ both catalytic systems show very similar behaviour. After 180 min on stream $\mathrm{VO}_{\mathrm{x}} / \mathrm{Al}_{2} \mathrm{O}_{3}$ shows a conversion of $50 \%$, a yield of $\mathrm{C}_{4} \mathrm{DH}$ products of $40 \%$ a selectivity to 1-butene of $48 \%$ and to 1,3-butadiene of $32 \%$. The corresponding values for the CNF are $41 \%, 32 \% 46 \%$ and $34 \%$ respectively. This similarity in catalytic behaviour between coked $\mathrm{VO}_{\mathrm{x}} / \mathrm{Al}_{2} \mathrm{O}_{3}$ and the $\mathrm{CNF}$ supports the hypothesis that carbonaceous deposits on the surface of the supported metaloxide catalyst are indeed active for $n$-butane dehydrogenation. Neither the CNFs, nor coked $\mathrm{VO}_{\mathrm{x}} / \mathrm{Al}_{2} \mathrm{O}_{3}$, exhibit deactivation as a function of increasing exposure to $n$-butane. It is also worth noting that very slight increases in the 1-butene selectivity are observed towards the end of the reaction period at low temperatures over $\mathrm{VO}_{\mathrm{X}} / \mathrm{Al}_{2} \mathrm{O}_{3}$. These
Table 2: Yield of $\mathrm{C}_{4} \mathrm{DH}$ products, conversion and selectivity to 1butene and to 1,3-butadiene obtained at $180 \mathrm{~min}$ during the direct dehydrogenation of $n$-butane over $\mathrm{CNFs}$ and $\mathrm{VO}_{\mathrm{x}} / \mathrm{Al}_{2} \mathrm{O}_{3}$ at $973 \mathrm{~K}$.

\begin{tabular}{clllll}
\hline Catalyst & $\begin{array}{l}\text { Reaction } \\
\text { temperature } \\
(\mathrm{K})\end{array}$ & $\begin{array}{l}\text { Yield } \\
(\%)\end{array}$ & $\begin{array}{l}\text { Conversion } \\
(\%)\end{array}$ & $\begin{array}{l}\text { Selectivity to } \\
\text { 1-butene }(\%)\end{array}$ & $\begin{array}{l}\text { Selectivity } \\
\text { to } 1, \\
\text { 3-butadiene }(\%)\end{array}$ \\
\hline $\mathrm{VO}_{x} / \mathrm{Al}_{2} \mathrm{O}_{3}$ & 973 & 40 & 50 & 48 & 32 \\
$\mathrm{PR} 24-\mathrm{LHT}$ & 973 & 32 & 41 & 46 & 34 \\
\hline
\end{tabular}

changes may also be due to the build-up of small amounts of active coke deposits.

While their role in the direct dehydrogenation of $n$-butane has not previously received attention coked $\mathrm{VO}_{\mathrm{X}} / \mathrm{Al}_{2} \mathrm{O}_{3}$ catalysts have previously been shown to exhibit slightly higher selectivity in the dehydrogenation of alkanes than as-prepared catalysts [5]. However, in that study the possible catalytic action of the coke was not considered. Increasing the selectivity of zeolite catalysts through carbon deposition is a strategy employed industrially in xylene isomerisation $[58,59]$. Furthermore, the activity of CNTs in the oxidative dehydrogenation of $n$-butane has recently been demonstrated [25]. As with the present work little or no deactivation was observed in the reaction on a carbonbased catalyst over the timescale investigated. Considering other reactant molecules, the activity of coke deposits and other carbonaceous materials in the ODH of ethylbenzene is well established with the activity of these known since at least the 1970s [60-62]. This area has been reviewed by Lisovskii and Aharoni [14], and by Cavani and Trifiro [15]. Similarly to the results reported herein, Lisovskii and Aharoni report that the activity of a metal-oxide catalyst reaches a steady-state after an induction period in which the entire catalyst surface is covered by carbonaceous material [14]. While the reaction mechanism may be different between ODH and direct DH reactions (the active sites for $n$ butane and ethylbenzene ODH over carbonaceous materials are believed to be carboxyl functionalities formed through oxidation of the carbon surface $[14,15,20,22,24,25,61$, 63]) there are a number of similarities between the nature of the active carbon. In both cases highly ordered materials represent excellent catalysts. Additionally, it has been noted by a number of authors that the activity of coke deposits in ethylbenzene ODH correlates with their degree of paramagnetism, with a greater concentration of unpaired electrons resulting in higher activity $[14,21,60]$. Such sites could also provide the active centres in the studies reported in the present work, since paramagnetic organic radicals were observed by EPR spectroscopy. The unpaired electrons present in such radicals may be capable of extracting hydrogen atoms from the $n$-butane feed, resulting in dehydrogenation. Both the deposition of new carbonaceous material (with associated paramagnetic centres) during reaction and the recombination of the extracted $\mathrm{H}$ atoms could then occur in such a way as to replenish the source of unpaired electrons.

The phenomenon of carbonaceous deposits providing, or enhancing, catalytic activity is not restricted to DH or ODH reactions. Intriguingly, carbonaceous overlayers 
formed on mineral surfaces during Fisher-Tropsch-type reactions have also been proposed as the active phase for catalytic reduction reactions in protostellar nebulae. Organic radicals present in such overlayers have been suggested as contributing to their catalytic activity [64]. Elsewhere, the hydrogenation of carbon-carbon double bonds over supported metal catalysts has been shown to be strongly dependent upon the nature of any deposited carbonaceous material [65]. Such reactions have been suggested to proceed, at least in part, through the transfer of hydrogen from an adsorbed hydrocarbonaceous overlayer onto which the reactant is adsorbed [66, 67]. Furthermore, carbon deposited during reaction plays a key role in the hydrogenation of alkynes over Pd catalysts, forming a catalytically active $P d-C_{x}$ surface phase $[68,69]$. Carbonaceous deposits and related materials therefore show activity in a wide number of reactions. The above data clearly show that the dehydrogenation of $n$-butane can be added to the list of reactions in which carbonaceous materials can provide high activity and selectivity.

\section{Conclusions}

It has been clearly demonstrated that highly ordered coke deposits are active for the dehydrogenation of $n$-butane. This conclusion is confirmed by complementary studies on unfunctionalised CNFs which, at $973 \mathrm{~K}$, demonstrate almost identical activity to coked $\mathrm{VO}_{\mathrm{x}} / \mathrm{Al}_{2} \mathrm{O}_{3}$. Organic radicals, associated with the carbonaceous material may play a role in the reaction mechanism. As this reaction proceeds successfully in the absence of gas-phase oxygen this activity is wholly attributable to the action of the carbonaceous material. Deactivation of the reaction is not

\section{References}

[1] R.E Kirk and D.F. Othmer (eds.), Kirk-Othmer Encyclopedia of Chemical Technology, John Wiley and Sons Inc., Hoboken, 2004

[2] J. McGregor, Z. Huang, G. Shiko, L.F. Gladden, R.S. Stein, M.J.Duer, Z.L. Wu, P.C. Stair, S. Rugmini, S.D. Jackson, Catalysis Today 142 (2009) 143.

[3] S.D. Jackson, S. Rugmini, P.C. Stair, Z.L. Wu, Z. L. Chemical Engineering Journal 120 (2006) 127.

[4] S.D. Jackson, S. Rugmini, Jounal of Catalysis 251 (2007) 59.

[5] Z.L. Wu, P.C. Stair, Journal of Catalysis 237 (2006) 220.

[6] Z. Huang, J. McGregor, P. Steiner, L.F. Gladden, S. Rugmini, S.D. Jackson, Magnetic Resonance Imaging 25 (2007) 562.

[7] E.M. Vass, M. Havecker, S. Zafeiratos, D. Teschner, A. Knop-Gericke, R. Schlögl, Journal of Physics-Condensed Matter 20 (2008) 184016.

[8] S.D. Jackson, P.C. Stair, L.F. Gladden, J, McGregor in: S.D. Jackson, J.S.J. Hargreaves (eds), Metal Oxide Catalysis, Wiley-VCH, Weinheim, 2008.

[9] A. Christodoulakis, M. Machli, A.A. Lemonidou, S. Boghosian, Journal of Catalysis 222 (2004) 293. observed in the timescale investigated, in stark contrast to behaviour at lower temperatures where rapid deactivation occurs. It is notable that commercially, alkane dehydrogenation also suffers from rapid deactivation at these lower reaction temperatures.

Additionally, $\mathrm{THz}$ spectroscopy is shown to be a valuable new resource in the catalyst characterisation toolkit. THz-TDS has the capability to distinguish between polyaromatic carbons on the basis of their long-range order and conductivity. Such discrimination is difficult to achieve by other methods, and as such THz-TDS will likely play an increasingly important role in future studies.

\section{Acknowledgements}

Support for this work was provided through the ATHENA project (EPSRC grant GR/R47523/01), funded by the Engineering and Physical Sciences Research Council and Johnson Matthey plc, and through Research Councils UK Basic Technology Programme (grants GR/R87086/02 and EP/E048811/1). Frank Girgsdies (FHI) is acknowledged for XRD measurements of the catalysts, Genka Tzolova-Mueller (FHI) for UV-vis spectroscopy, while Christian Hess is thanked for assistance in conducting the Raman spectroscopy experiments. The authors would also like to thank Professor Peter Stair, Dr. Zili Wu (Northwestern University, USA) Professor S. David Jackson, and Dr. Sreekala Rugmini (University of Glasgow, UK) for helpful discussions. The BESSY staff are gratefully acknowledged for their continuing support of our measurements.
[10] O.R. Evans, A.T. Bell, T.D. Tilley, Journal of Catalysis 226 (2004) 292

[11] M.A. Bañares, Catalysis Today 51 (1999) 319.

[12] T. Blasco, J.M.L. Nieto, Applied Catalysis A: General 157 (1997) 117.

[13] F. Cavani, N. Ballarini, A. Cericola, Catalysis Today 127 (2007) 113.

[14] A.E. Lisovskii, C. Aharoni, Catalysis Reviews-Science and Engineering 36 (1994) 25.

[15] F. Cavani, F. Trifiro, Applied Catalysis A: General 133 (1995) 219.

[16] A. Guerrero-Ruiz, I. Rodriguez-Ramos, Carbon 32 (1994) 23.

[17] M.F.R. Pereira, J.J.M. Orfao, J.L. Figueiredo, Applied Catalysis A: General 184 (1999) 153

[18] M.F.R. Pereira, J.J.M. Orfao, J.L. Figueiredo, Applied Catalysis A: General 196 (2000) 43.

[19] M.F.R. Pereira, J.J.M. Orfao, J.L. Figueiredo, Applied Catalysis A: General 218 (2001) 307.

[20] J.A. Macia-Agullo, D. Cazorla-Amoros, A. Linares-Solano, U. Wild, D.S. Su, R. Schlögl, Catalysis Today, 102-103 (2005) 248. 
[21] L.E. Cadus, L.A.Arrua, O.F. Gorriz, J.B. Rivarola, Industrial \& Engineering Chemistry Research, 27 (1988) 2241.

[22] D.S. Su, N. Maksimova, J.J. Delgado, N. Keller, G. Mestl, M.J. Ledoux, R. Schlögl, Catalysis Today 102-103 (2005) 110.

[23] N. Keller, N.I. Maksimova, V.V. Roddatis, M. Schur, G. Mestl, Y.V. Butenko, V.L. Kuznetsov, R. Schlögl, Angewandte Chemie-International Edition 41 (2002) 1885.

[24] G. Mestl, N.I. Maksimova, N. Keller, V.V. Roddatis, R. Schlögl, Angewandte Chemie-International Edition $\mathbf{4 0}$ (2001) 2066.

[25] J. Zhang, X. Liu, R. Blume, A. Zhang, R. Schlögl, D.S. Su, Science 322 (2008) 73.

[26] Z.L. Wu, H.-S. Kim, P.C. Stair, S. Rugmini, S.D. Jackson, Journal of Physical Chemistry B 109 (2005) 2793.

[27] G.G. Tibbetts, M.L. Lake, K.L. Strong, B.P. Rice, Composites Science and Technology, 67 (2007) 1709.

[28] A. Sadezky, H. Muckenhuber, H. Grothe, R. Niessner, U. Poschl, Carbon 43 (2005) 1731.

[29] P.C. Upadhya, K.L. Nguyen, Y.C. Shen, J. Obradovic, K. Fukushige, R. Griffiths, L.F. Gladden, A.G. Davies, E.H. Linfield, Spectroscopy Letters 39 (2006) 215.

[30] E.P.J. Parrott, J.A. Zeitler, J. McGregor, S.-P. Oei, H.E. Unalan, S.-C. Tan, W.I. Milne, J.-P. Tessonnier, R. Schlögl, L.F. Gladden, L. F. The Journal of Physical Chemistry C 113 (2009) 10554.

[31] J.A. Zeitler, P.F. Taday, D.A. Newnham, M. Pepper, K.C. Gordon, T. Rades, Journal of Pharmacy and Pharmacology 59 (2007) 209.

[32] Z.L. Wu, H.-S. Kim, P.C. Stair in: S.D. Jackson, J.S.J. Hargreaves (eds) Metal Oxide Catalysis, Wiley-VCH, Weinheim, 2008.

[33] McGregor, J., Solid-State NMR of Oxidation Catalysts, in Metal Oxide Catalysis, Jackson SD and Hargreaves JSJ [eds], Wiley-VCH, Weinheim, 2008

[34] Z.L. Wu, P.C. Stair, S. Rugmini, S.D. Jackson, Journal of Physical Chemistry C 111 (2007) 16460.

[35] B.M. Weckhuysen, D.E. Keller, Catalysis Today 78 (2003) 25.

[36] S.M.K. Airaksinen, M.E. Harlin, A.O.I. Krause, Industrial \& Engineering Chemistry Research 41 (2002) 5619.

[37] M. Baltes, P. van der Voort, B.M. Weckhuysen, R.R. Rao, G. Catana, R.A. Schoonheydt, E.F. Vansant, Physical Chemistry Chemical Physics 2 (2000) 2673.

[38] R. Gallay, J.J. Vanderklink, J. Moser, Physical Review B 34 (1986) 3060.

[39] J.M. Rojo, J.L. Mesa, R. Calvo, L. Lezama, R. Olazcuaga, T. Rojo, Journal of Materials Chemistry 8 (1998) 1423.

[40] F. Cavani, F. Trifiro, Catalysis Today 24 (1995) 307.

[41] E.M. Vass, D. Teschner, A. Knop-Gericke, R. Schlögl, R. unpublished work.

[42] H. Bosch, B.J. Kip, J.G. Vanommen, P.J. Gellings, Journal of the Chemical Society-Faraday Transactions I 80 (1984) 2479.

[43] D.B. McWhan, J.P. Remeika, Physical Review B 2 (1970) 3734.
[44] E.P.J. Parrott, J.A. Zeitler, J. McGregor, S.-P. Oei, W.I. Milne, J.-. Tessonnier, D.S. Su, R. Schlögl, L.F. Gladden, Advanced Materials 21 (2009) 3953

[45] N. Hisaaki, M. Nobutsugu, S. Ryo, Applied Physics Letters 91 (2007) 011108.

[46] K. Chul, M. In Hee, O. Seung Jae, L. Seong Chu, A. Kay Hyeok, L. Young Hee, S. Joo-Hiuk, S. Physical Review B (Condensed Matter and Materials Physics) 75 (2007) 085410.

[47] B. Paweewan, P.J. Barrie, L.F. Gladden, L. F. Applied Catalysis A: General 185 (1999) 259.

[48] B.R. Richardson, J.F. Haw, Analytical. Chemistry. 61 (1989) 1821.

[49] J.L. Bonardet, M.C. Barrage, J. Fraissard, J. Journal of Molecular Catalysis A: Chemical 96 (1995) 123.

[50] R.H. Meinhold, D.M. Bibby, Zeolites 10 (1990) 121.

[51] C.J. Rhodes, C.S. Hinds, Molecular Engineering 4 (1994) 119.

[52] J. Tarabek, L. Kavan, M. Kalbac, P. Rapta, M. Zukalova, L. Dunsch, Carbon 44 (2006) 2147.

[53] V. Likodimos, S. Glenis, N. Guskos, C.L. Lin, Physical Review B 68 (2003) 045417.

[54] F. Cavani, F. Trifirò, Catalysis Today 51 (1999) 561.

[55] Y.T. Chua, P.C. Stair, Journal of Catalysis 213 (2003) 39.

[56] S. Kuba, H. Knozinger, Journal of Raman Spectroscopy 33 (2002) 325.

[57] J. Schwan, S. Ulrich, V. Batori, H. Ehrhardt, S.R.P. Silva, Journal of Applied Physics 80 (1996) 440.

[58] F. Bauer, W.-H. Chen, Q. Zhao, A. Freyer, S.-B. Liu, Microporous and Mesoporous Materials 47 (2001) 67.

[59] J.S. Beck, R.A. Crane, M.F. Mathias, J.A. Kowalski, D.N. Lissy, D.L. Stern, WO Patent 9952842 (1999) to Mobil Oil Corporation.

[60] R. Fiedorow, W. Przystajko, M. Sopa, I.G. Dalla Lana, Journal of Catalysis 68 (1981) 33.

[61] A. Schraut, G. Emig, H.G. Sockel, Applied Catalysis 29 (1987) 311

[62] T.G. Alkhazov, A.E. Lisovskii, Kinetika i Kataliz 17 (1976) 434.

[63] G. Emig, H. Hofmann, Journal of Catalysis 84 (1983) 15

[64] J.A. Nuth, N.M. Johnson, S. Manning, Astrophysical Journal Letters 673 (2008) L225.

[65] J. McGregor, L.F. Gladden, Applied Catalysis A: General 345 (2008) 51

[66] S.J. Thomson, G. Webb, Journal of the Chemical Society: Chemical Communications (1976) 526.

[67] S.D. Jackson, C.A. Hamilton, G.J. Kelly, D. de Bruin, D. Reaction Kinetics and Catalysis Letters 73 (2001) 77.

[68] D. Teschner, E.M. Vass, M. Havecker, A. Zafeiratos, P. Schnorch, H. Sauer, A. Knop-Gericke, R. Schlögl, M. Chamam, A. Wootsch, A.S. Canning, J.G. Gamman, S.D. Jackson, J. McGregor, L.F. Gladden, Journal of Catalysis 242 (2006) 26

[69] D. Teschner, J. Borsodi, A. Wootsch, Z. Revay, M. Havecker, A. Knop-Gericke, S.D. Jackson, R. Schlögl, Science 320 (2008) 86. 